\title{
Bildung ist überall
}

Lebenslanges Lernen ist längst vom Schlagwort zur Realität geworden. In vielen Branchen ist Veränderung so allgegenwärtig, dass Mitarbeitern gar nichts anderes übrig bleibt, als sich ständig weiterzubilden. Gleichzeitig nimmt der Zeitdruck am Arbeitsplatz zu. Da wird es schwierig, sich für ein paar Tage auszuklinken, um eine Fortbildung zu besuchen.

Weiterbildung aus dem Netz, also online-basiertes Lernen, bietet in dieser Hinsicht klare Vorteile. Keine Reisezeiten, der einzelne Mitarbeiter kann lernen, wenn sich in seinem persönlichen Zeitplan Lücken ergeben und das von jedem Ort mit Zugang zum Internet aus. Je nach individuellem Ziel und Bedürfnis kann ein Kurs mit gleichem Inhalt intensiv in kurzer Zeit oder in kleinen Portionen über einen längeren Zeitraum absolviert werden.

Andererseits hat auch das Präsenzlernen, die Möglichkeit, sich direkt mit Dozenten oder anderen Lernenden auszutauschen, unbestreitbare Vorteile. Viele setzen deshalb auf eine gesunde Mischung. Das sogenannte Blended Learning erfreut sich großer Beliebtheit. Auch an Universitäten werden in Massive Open Online Courses (MOOC) die Möglichkeiten des Lernens vor dem heimischen Rechner statt im Hörsaal zunehmend genutzt. So eröffnen Hochschulen neue Möglichkeiten der Vereinbarkeit von Arbeiten und Lernen - etwa für Berufstätige, die sich nebenbei qualifizieren möchten. Man darf gespannt sein, wie sich dieser Bereich in den kommenden Jahren noch weiterentwickeln wird.

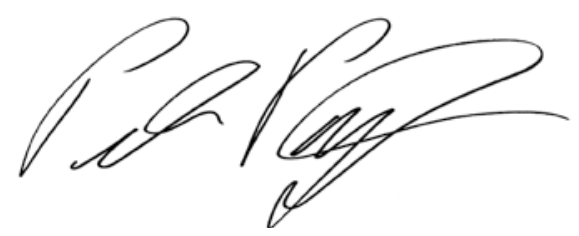

Peter Pagel

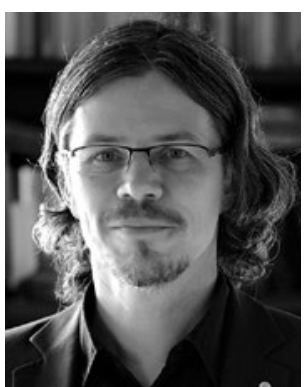

Peter Pagel

Chefredakteur 